\title{
A Comparative Study Towards the Establishment of an Automatic Retinal Vessel Width Measurement Technique
}

Citation for published version (APA):

Huang, F., Dashtbozorg, B., Yeung, A. K. S., Zhang, J., Berendschot, T. T. J. M., \& ter Haar Romeny, B. M. (2017). A Comparative Study Towards the Establishment of an Automatic Retinal Vessel Width Measurement Technique. In M. J. Cardoso, T. Arbel, A. Melbourne, H. Bogunovic, P. Moeskops, X. Chen, E. Schwartz, M. Garvin, E. Robinson, E. Trucco, M. Ebner, Y. Xu, A. Makropoulos, A. Desjardin, \& T. Vercauteren (Eds.), Fetal, Infant and Ophthalmic Medical Image Analysis (pp. 227-234). Springer. Lecture Notes in Computer Science https://doi.org/10.1007/978-3-319-67561-9_26

Document status and date:

Published: 01/01/2017

DOI:

10.1007/978-3-319-67561-9 26

Document Version:

Publisher's PDF, also known as Version of record

\section{Document license:}

Taverne

Please check the document version of this publication:

- A submitted manuscript is the version of the article upon submission and before peer-review. There can be important differences between the submitted version and the official published version of record.

People interested in the research are advised to contact the author for the final version of the publication, or visit the DOI to the publisher's website.

- The final author version and the galley proof are versions of the publication after peer review.

- The final published version features the final layout of the paper including the volume, issue and page numbers.

Link to publication

\footnotetext{
General rights rights.

- You may freely distribute the URL identifying the publication in the public portal. please follow below link for the End User Agreement:

www.umlib.nl/taverne-license

Take down policy

If you believe that this document breaches copyright please contact us at:

repository@maastrichtuniversity.nl

providing details and we will investigate your claim.
}

Copyright and moral rights for the publications made accessible in the public portal are retained by the authors and/or other copyright owners and it is a condition of accessing publications that users recognise and abide by the legal requirements associated with these

- Users may download and print one copy of any publication from the public portal for the purpose of private study or research.

- You may not further distribute the material or use it for any profit-making activity or commercial gain

If the publication is distributed under the terms of Article $25 \mathrm{fa}$ of the Dutch Copyright Act, indicated by the "Taverne" license above, 


\title{
A Comparative Study Towards the Establishment of an Automatic Retinal Vessel Width Measurement Technique
}

\author{
Fan Huang ${ }^{1(\bowtie)}$, Behdad Dashtbozorg ${ }^{1}$, Alexander Ka Shing Yeung ${ }^{2}$, \\ Jiong Zhang ${ }^{1}$, Tos T.J.M. Berendschot ${ }^{2}$, and Bart M. ter Haar Romeny ${ }^{1,3}$ \\ 1 Department of Biomedical Engineering, Eindhoven University of Technology, \\ Eindhoven, The Netherlands \\ $\{$ F.Huang, B.DashtBozorg, J .Zhang1, B.M.TerHaarRomeny\}@tue.nl \\ 2 University Eye Clinic Maastricht, Maastricht, The Netherlands \\ 3 Department of Biomedical and Information Engineering, Northeastern University, \\ Shenyang, China
}

\begin{abstract}
In this paper, we propose an automatic technique for the assessment of retinal vessel caliber in fundus images using a fully automatic technique exploiting a multi-scale active contour technique. The proposed method is compared with the well-known semi-automated IVAN software and the Vampire width annotation tool. Experimental results show that our approach is able to provide fast and fully automatic caliber measurements with similar caliber measurement and comparable system error as the IVAN software. It will benefit the analysis of quantitative retinal vessel caliber measurements in large-scale screening programs.
\end{abstract}

Keywords: Vessel width • Arteriolar-to-venular ratio $\cdot$ Fundus images • Active contour · Diabetes

\section{Introduction}

Many clinical studies have shown that the changes in retinal vessel caliber are associated with the progress of a variety of systemic diseases. In diabetic retinopathy (DR), the narrowing on arterioles and the widening on venules are observed, which result in a lower arteriolar-to-venular diameter ratio (AVR) $[8,11]$. Moreover, a decrease in generalized arteriolar diameter is associated with a higher risk of developing hypertension [7], and an increase on venular diameter is associated with renal failure, systemic inflammation and stroke [11].

Most works on assessing the change of vascular caliber on fundus images still rely on a semi-automatic tool: Eye-van (IVAN), which was developed at the University of Wisconsin, USA $[3,4,10]$. However, it takes approximate 7-10 min to obtain the precise width measurement of vessels, which includes the time of automatic vessel detection and classification, manual cropping, adding vessel segments and correcting their labels. Using IVAN in large-scale screening programs 
is therefore too much time consuming, exhausting and prone to human error. Developing a fully automatic system for large-scale vessel caliber assessment is still an open challenge.

In this paper, we propose an automatic and precise quantitative width measurement for retinal blood vessels. We validate the technique by comparing the results with the IVAN software and the Vampire width annotation tool, where the former one is semi-automatic measurement and the latter is a manual measurement.

\section{Methodology}

The proposed method for automatic vessel caliber measurement uses the centerline of a segmented blood vessel for initializing a deformable enclosed contour. Then the contour is evolved iteratively and fitted to the boundaries of the vessel. Finally, the vessel caliber is measured by computing the distance from one detected vessel edge to the other one. The stages are summarized in Fig. 1.

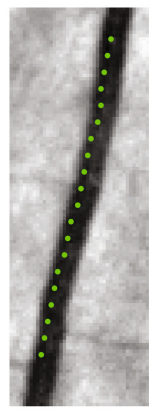

(a)

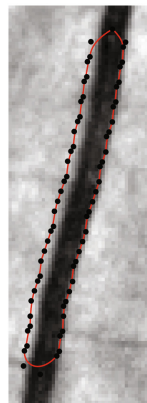

(b)

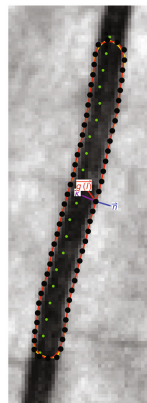

(c)

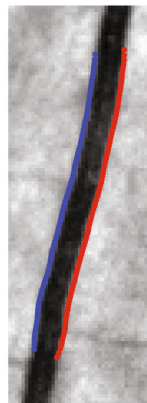

(d)

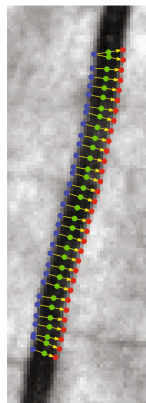

(e)

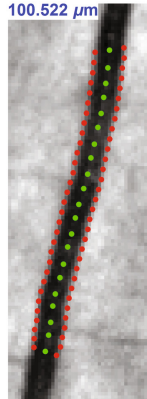

(f)

Fig. 1. The stages of the proposed automatic width measurement technique: (a) centerline detection; (b) contour initialization; (c) active contour segmentation; (d) obtaining the left and right edges; (e) Euclidean distance calculation and (f) vessel caliber estimation.

(a) Vessel centerline extraction. The proposed method is initialized by automatically extracting the vascular tree. We used the vessel segmentation technique proposed in [12], which employs a set of multi-scale Gaussian derivative filters rotated to different directions in so-called 'orientation-scores'. This method provides an enhanced vessel map, which is then converted to a binary vascular map using a proper threshold value. The vessel segmentation is skeletonized by an iterative thinning algorithm to obtain the centerline of the vasculature. Junction points like vessel branchings and crossings are removed, resulting in a map of individual separated vessel segments. 
(b) Artery/vein classification. The separated vessel segments are automatically classified into arteries and veins by a supervised classifier. In the training phase, a logistic regression classifier is trained by a dataset of 60 images, which are acquired by the same Canon camera. For each vessel centerline pixel, we extract in total 455 features including: the local intensity of RGB and HSB color channels; the mean, standard deviation, median, minimum and maximum of the intensities inside small, medium and large circular regions; the intensity values along each vessel centerline; and the intensity inside each vessel segment. After that, a genetic-search based feature selection approach is used to select a subset of features giving the highest classification accuracy. Finally, the classifier is trained with the selected features of the training data and used for the classification of arteries and veins in this study.

(c) Vessel caliber measurement. In this step, the geodesic active contour model proposed in [1] for solving a global optimization problem is exploited to locate the left and right edges for each vessel segment. First of all, an enclosed and deformable contour $\mathbf{x}(t)=(x(t), y(t))(t \in(0,1))$ is initialized using the extracted centerline pixels. Afterwards, the surface is iteratively deformed to minimize the energy function:

$$
E(\mathbf{x})=\int_{0}^{1} E_{\text {int }}(\mathbf{x}(t))+E_{\text {ext }}(\mathbf{x}(t))+E_{\text {con }}(\mathbf{x}(t)) d t
$$

where $E_{\text {int }}$ (internal energy) is resulted by the force of the interaction between adjacent control points, which preserves the smoothness of the surface. While $E_{\text {ext }}$ (external energy) is resulted by the image gradient which pulls the contour toward vessel boundary, and $E_{\text {con }}$ (constraint energy) is resulted by a constraint for the external force. Therefore, at each iteration, the control points follow the contour evolution equation:

$$
\begin{gathered}
\frac{\partial \mathbf{x}(t))}{\partial t}=\alpha g(I)(c+\kappa) \vec{n}+\beta(\nabla g(I) \cdot \vec{n}) \vec{n}+\gamma \nabla \mathbf{x}(t) \cdot \nabla g(I), \\
g(I)=\frac{1}{1+\nabla I^{2}},
\end{gathered}
$$

where $I(x, y)$ is the image and $\nabla I$ is the first-order Gaussian derivative of $I, \kappa$ and $\vec{n}$ are the Euclidean curvature and the unit normal vector of $\mathbf{x}(\mathrm{t}) \cdot g(I)$ is the speed function given $\nabla I$ and $c, \alpha, \beta$ and $\gamma$ are weighting parameters. Contour evolution is terminated when a stop criterion (e.g. after a certain number of iterations) is satisfied, resulting in a smooth vessel edges detection.

Vessel caliber is then estimated using the evolved contour. The contour is split into left and right edges by removing the control points at the two ends of the vessel segments. For each control point on one side of the vessel, a corresponding nearest point is found on a B-spline interpolated curve of two nearest points on the other side. The Euclidean distance between each two points is computed and converted to micrometer $\mu m$ using the pixel size of each image. We estimate the pixel size by taking the ratio between the general optic disc diameter $(1800 \mu \mathrm{m})$ 
and the diameter in pixels measured by the method described in [2]. In order to prevent outliers, the measured distances with extreme values are eliminated and the vessel width is calculated as the average of the remained measurements.

(d) CRAE, CRVE and AVR measurement. The results are used for estimating the central retinal arterial equivalent (CRAE) and the central retinal venous equivalent (CRVE) (see Fig. 2). Firstly, the optic disc center and diameter are obtained using the super-elliptical convergence filters proposed in [2]. Then, the vessels within the standard area of 0.5 to 1.0 disc diameter around the disc center are selected and the width values are fed to the Knudtson's revised formulas [6]. Finally, the AVR value is defined as the ratio between the CRAE and CRVE.

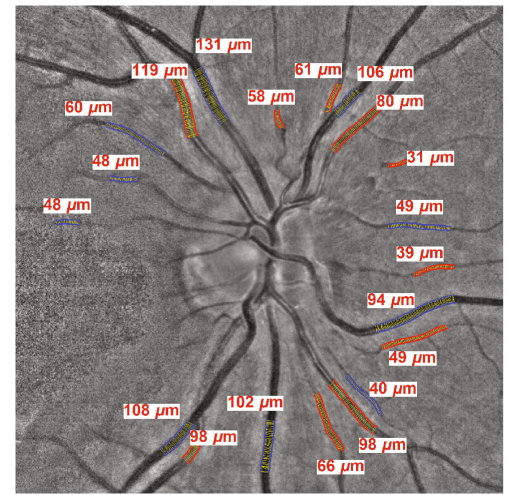

(a)

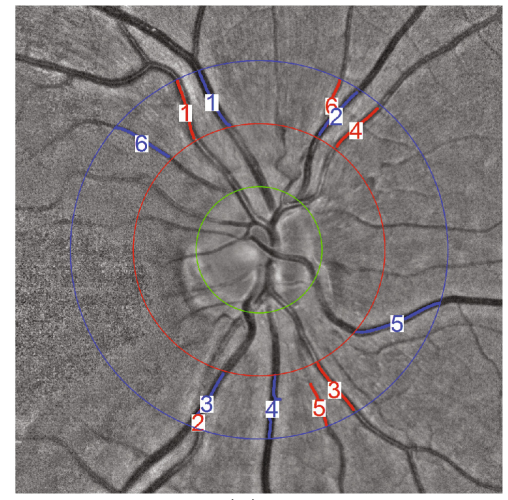

(b)

Fig. 2. The vessels within the standard region are selected for calculating the CRAE and CRVE values: (a) the widths of selected vessel are measured by the proposed method; (b) The six largest arteries and veins are then selected for the calculation of CRAE, CRVE and AVR values.

\section{Experimental Result}

\subsection{Study Population}

The study includes a group of 15 healthy volunteers ( 7 men and 8 women) with age between 20 and 60 years. For each subject, 5 optic-disc centered images were repeatedly acquired on the right eyes using a Canon Cr-1 Mark II fundus camera, with image resolution of $3627 \times 2178$ pixels. The images are used for the quantitative cross-sectional comparative study between the three caliber assessment methods. 


\subsection{Vessel Width Measurement Tools}

IVAN Tool developed by the University of Wisconsin, USA, is a program for assessing the blood vessels caliber on fundus images (see Fig. 3(a)). First of all, it automatically locates the center of the optic disc and determines a standard area of 0.5 to 1.0 disc diameter around it. The vessels within the region-ofinterest (ROI) are detected and their calibers are measured as the average distance between the vessel left and right edges. In addition, the detected vessels are classified as artery and vein for the measurement of CRAE and CRVE. After the automatic processing, a manual correction is performed by the user. It includes adjusting the position of the optic disc center, adding the miss-detected vessels, correcting the vessel labels and eliminating the wrongly detected vessel edges. When the manual correction is done, the tool computes the values of CRAE, CRVE and AVR using the Paired, the Parr-Hubbard [5], and the Knudtson's revised formulas [6].

Vampire Tool [9] developed by the University of Dundee, Scotland, is used for the manual measurement of vessel width (see Fig. 3(b)). The instructions of the program require clicking the vessels around the optic disc region to measure and determine their vessel type simultaneously. Then for each vessel, the left and right edges need to be clicked and the Euclidean distance between them is considered as the width of the vessel. Finally, the values of the CRAE, CRVE and AVR are computed using the Knudtson's revised formulas [6].

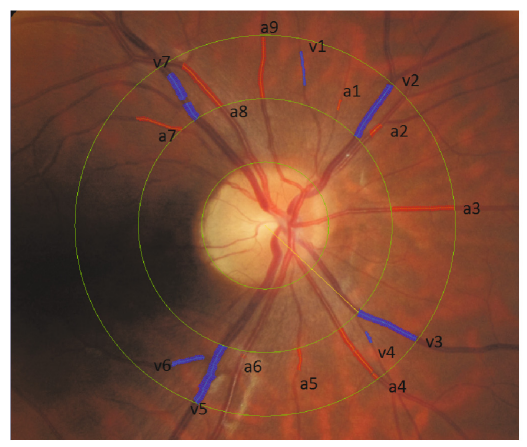

(a) IVAN - display panel

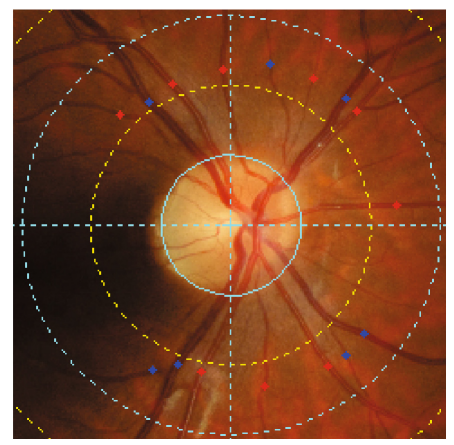

(b) Vampire - display panel

Fig. 3. The user interfaces for the IVAN and the Vampire tools. (a) The IVAN software measures vessel calibers by automatic processing and manual modification. (b) The Vampire annotation tool is used for measuring vessel calibers manually.

\section{$3.3 \quad$ Results}

The system error indicates the robustness of a tool on measuring biomarkers for the same vasculature acquired in multiple acquisitions. In this study, it is calculated by taking the average of the relative errors (mean/standard deviation) 
Table 1. The relative error of the CRAE, CRVE and AVR values obtained by the proposed method, IVAN and Vampire tools.

\begin{tabular}{l|l|l|l|l}
\hline \multirow{2}{*}{ Software } & \multicolumn{4}{|l}{ Relative error } \\
\cline { 2 - 5 } & CRAE & CRVE & AVR & Average \\
\hline Our method & $2.84 \%$ & $2.40 \%$ & $3.20 \%$ & $2.81 \%$ \\
\hline IVAN & $2.32 \%$ & $1.91 \%$ & $2.65 \%$ & $2.29 \%$ \\
\hline Vampire & $4.09 \%$ & $3.63 \%$ & $5.73 \%$ & $4.48 \%$ \\
\hline
\end{tabular}

among 5 acquisitions on 15 subjects. The results are shown in Table 1 . Comparing the error of three tools, as expected the Vampire annotation tool produces the largest variation among the three tools, which is two times larger than the other two tools. The calibers obtained by manual vessel annotation are clearly prone to human error.

We examined the correlation of the measurements obtained by our proposed method and the IVAN tool. Figure 4 shows the scatter plots for the CRAE, CRVE and AVR respectively by the two tools. $p c c$ represents the Pearson's correlation coefficient and $p$ is the corresponding $p$-value. Considering the confidence interval 95\% ( $p=0.05)$, the results of CRAE, CRVE and AVR obtained by two tools are significantly correlated. It implies that the proposed automatic tool produces similar caliber values compared to IVAN.

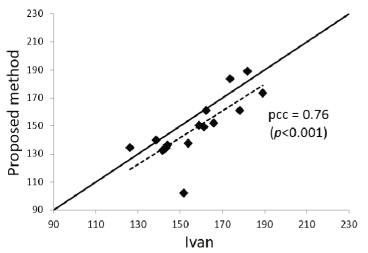

(a) CRAE

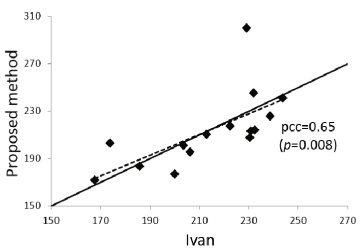

(b) CRVE

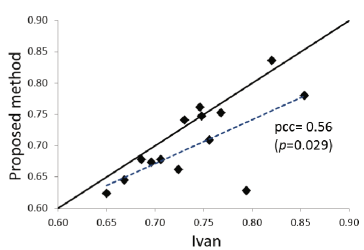

(c) AVR

Fig. 4. Scatter plots for comparing the (a) CRAE, (b) CRVE and (c) AVR obtained by our method and the IVAN tool on the retinal images acquired using the Canon camera. The dashed line show the linear regression line for the data points.

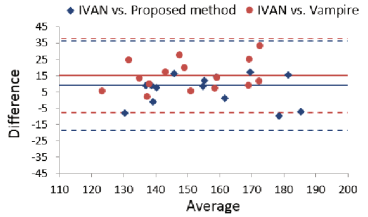

(a) CRAE

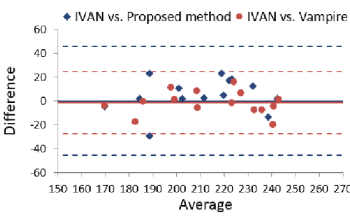

(b) CRVE

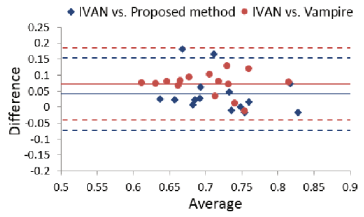

(c) AVR

Fig. 5. The Bland-Altman plots for comparing the (a) CRAE, (b) CRVE and (c) AVR values obtained by our method and the Vampire tool with the IVAN. 
The Bland Altman plots in Fig. 5 compare the proposed method and the Vampire annotation tool using the IVAN software as the reference. The CRAE values measured by our method have better agreement with the values obtained from the IVAN, where it has a lower bias than the Vampire. In the case of measuring CRVE, the performance of both tools is similar, with almost zero bias, though the error of the Vampire is lower than our method. For measuring AVR, which is an important clinical relevant biomarker in large-scale setting, our fully automatic method produces much accurate results than the human annotation tool, with lower bias and variation.

The assessment of vascular caliber using the proposed method takes around $8 \mathrm{~min}$ on one image from the described dataset. In detail, the vessel segmentation, artery/vein classification and vessel caliber measurement steps respectively take 2, 4 and 2 min on a single core CPU. Since the full processing is automatic, the calculation time reduced to less than 1 min per image when we process the images in a parallel setting with a 12 cores $2.30 \mathrm{GHz}$ CPU and $128 \mathrm{~GB}$ of RAM.

\section{Conclusion}

In conclusion, we propose an automatic technique for the vessel caliber measurement on retinal photographs, which will be used in a large-scale retinal screening program. We validate this method on a dataset consisting of images acquired on 15 healthy subjects, each of which receives 5 repeated acquisitions. In addition, we compare our tool with the semi-automatic tool - IVAN and the manual vessel annotation tool - Vampire. The result shows the superiority of the proposed automatic vessel caliber measurement. Additionally, IVAN requires time-consuming human attention to modify the automatic generated result, which prohibits analyzing great amounts of data. The proposed method is able to provide automatic caliber measurements with a comparable system error and similar CRAE, CRVE measurements to IVAN. It will enable fully quantitative retinal vessel caliber analysis in large-scale screening programs.

Acknowledgments. The work is part of the Hé Programme of Innovation Cooperation, which is financed by the Netherlands Organization for Scientific Research (NWO), dossier No. 629.001.003.

\section{References}

1. Caselles, V., Kimmel, R., Sapiro, G.: Geodesic active contours. Int. J. Comput. Vision 22(1), 61-79 (1997)

2. Dashtbozorg, B., Zhang, J., Huang, F., ter Haar Romeny, B.M.: Automatic optic disc and fovea detection in retinal images using super-elliptical convergence index filters. In: Campilho, A., Karray, F. (eds.) ICIAR 2016. LNCS, vol. 9730, pp. 697706. Springer, Cham (2016). doi:10.1007/978-3-319-41501-7_78

3. Drobnjak, D., Munch, I.C., Glümer, C., Faerch, K., Kessel, L., Larsen, M., Veiby, N.C.: Retinal vessel diameters and their relationship with cardiovascular risk and all-cause mortality in the inter99 eye study: a 15-year follow-up. J. Ophthalmol. 2016, 1-8 (2016) 
4. Frydkjaer-Olsen, U., Soegaard Hansen, R., Simó, R., Cunha-Vaz, J., Peto, T., Grauslund, J., et al.: Correlation between retinal vessel calibre and neurodegeneration in patients with type 2 diabetes mellitus in the european consortium for the early treatment of diabetic retinopathy (eurocondor). Ophthalmic Res. 56(1), 10-16 (2016)

5. Hubbard, L.D., Brothers, R.J., King, W.N., Clegg, L.X., Klein, R., Cooper, L.S., Sharrett, A.R., Davis, M.D., Cai, J., Atherosclerosis Risk in Communities Study Group, et al.: Methods for evaluation of retinal microvascular abnormalities associated with hypertension/sclerosis in the atherosclerosis risk in communities study. Ophthalmology 106(12), 2269-2280 (1999)

6. Knudtson, M.D., Lee, K.E., Hubbard, L.D., Wong, T.Y., Klein, R., Klein, B.E.: Revised formulas for summarizing retinal vessel diameters. Curr. Eye Res. 27(3), 143-149 (2003)

7. Neubauer, A.S., Luedtke, M., Haritoglou, C., Priglinger, S., Kampik, A.: Retinal vessel analysis reproducibility in assessing cardiovascular disease. Optom. Vis. Sci. 85(4), E247-E254 (2008)

8. Nguyen, T.T., Wong, T.Y.: Retinal vascular changes and diabetic retinopathy. Curr. Diab.Rep. 9(4), 277-283 (2009)

9. Perez-Rovira, A., MacGillivray, T., Trucco, E., Chin, K., Zutis, K., Lupascu, C., Tegolo, D., Giachetti, A., Wilson, P., Doney, A., et al.: Vampire: vessel assessment and measurement platform for images of the retina. In: 2011 Annual International Conference of the IEEE Engineering in Medicine and Biology Society, EMBC, pp. 3391-3394. IEEE (2011)

10. Shin, Y.U., Lee, S.E., Cho, H., Kang, M.H., Seong, M.: Analysis of peripapillary retinal vessel diameter in unilateral normal-tension glaucoma. J. Ophthalmol. 2017, 1-7 (2017)

11. Sun, C., Wang, J.J., Mackey, D.A., Wong, T.Y.: Retinal vascular caliber: systemic, environmental, and genetic associations. Surv. Ophthalmol. 54(1), 74-95 (2009)

12. Zhang, J., Bekkers, E., Abbasi, S., Dashtbozorg, B., ter Haar Romeny, B.M.: Robust and fast vessel segmentation via Gaussian derivatives in orientation scores. In: Murino, V., Puppo, E. (eds.) ICIAP 2015. LNCS, vol. 9279, pp. 537-547. Springer, Cham (2015). doi:10.1007/978-3-319-23231-7_48 